Saudi Journal of Oral and Dental Research

Abbreviated Key Title: Saudi J Oral Dent Res

ISSN 2518-1300 (Print) |ISSN 2518-1297 (Online)

Scholars Middle East Publishers, Dubai, United Arab Emirates

Journal homepage: https://saudijournals.com

\title{
Band and Loop Space Maintainers in Children: A Case Series
}

Anindita Talukdar ${ }^{1 *}$, Pushpalatha $\mathrm{C}^{2}$, Prakash Chandra ${ }^{3}$, Diganta Borah ${ }^{4}$

${ }^{1}$ Private Consultant, Pedodontist Guwahati, House No. 87 Dhirenpara Itabhata Road Guwahati 781025, Assam, India

${ }^{2}$ Associate Professor, Department of Pedodontics and Preventive Dentistry, Faculty of Dental Sciences, M. S. Ramaiah University of Applied Sciences, Bengaluru, India

${ }^{3}$ Professor, Department of Pedodontics and Preventive Dentistry, Faculty of Dental Sciences, M. S. Ramaiah University of Applied Sciences, Bengaluru, India

${ }^{4}$ Private Practitioner Guwahati, Assam, India

DOI: $\underline{10.36348 / \text { sjodr.2021.v06i02.004 }}$

| Received: 05.02.2021 | Accepted: 16.02.2021 | Published: 18.02.2021

*Corresponding author: Dr. Anindita Talukdar

\section{Abstract}

Space maintainers are the most commonly used appliances to preserve the spaces in primary dentition created due to untimely loss of deciduous dentition. Maintaining the lost space is of utmost importance for the developing occlusion and guidance to the succedinuos tooth as well as maintaining function and integrity of the jaw bone. The band and loop space maintainer is one of the most widely used space maintainer, however depending on the individual cases and anatomy of the supporting structures the traditional band and loop space maintainers can be modified to meet the individual requirements. This article presents case reports of modified band and loop space maintainers.

Keywords: Band and loop, space maintainers, modified band and loop.

Copyright (C) 2021 The Author(s): This is an open-access article distributed under the terms of the Creative Commons Attribution 4.0 International License (CC BY-NC 4.0) which permits unrestricted use, distribution, and reproduction in any medium for non-commercial use provided the original author and source are credited.

\section{INTRODUCTION}

Deciduous dentition has an important role to play in the development of occlusion. The disadvantages of premature loss of primary teeth include reduced arch length, crowding, crossbite in the first permanent molar area, reduced masticatory function and accumulation of plaque material and food debris, which will often result in increased dental caries activity and gingival inflammation [1]. However management of space depends on the child's stage of dental development, dental arch involved, number of primary teeth missing, child's oral health condition, occlusion may also be a factor in determining the type of space maintainer [2]. The band and loop space maintainer has few limitations like having the loop extended lingualy which might interfere with the child's tongue and eventually dislodging the loop in the long run. Considering all these limitations, three cases are being discussed in this article, which not only can be delivered in a single sitting but also reduces a number of fabrication steps. This appliance saves a lot of time both for the dentist and for the patient and may be proven as a good alternative to the conventional band and loop space maintainer.

\section{CASE REPORT}

Case-1

A 9 year old male patient reported to the department of Pedodontics and Preventive Dentistry with the complain of decayed tooth. On examination the left lower primary second molar was grossly decayed and intra oral radiograph showed resorbed roots. A treatment plan of extraction of the decayed tooth followed by placement of a space maintainer was chosen. Since the permanent molar was fully erupted and space maintainence was needed for a lesser duration a bonded space maintainer was fabricated as in Figure-1. The treatment was done in a single visit with chairside fabrication of the unilateral loop with 19 gauge stainless steel wire wire. The mesial and distal ends of the loop were bonded using resin cement on the primary first molar mesially and permanent first molar distally. Patient was recalled after 1 week and there was no discomfort and maintainence of oral hygiene was good with this appliance. 

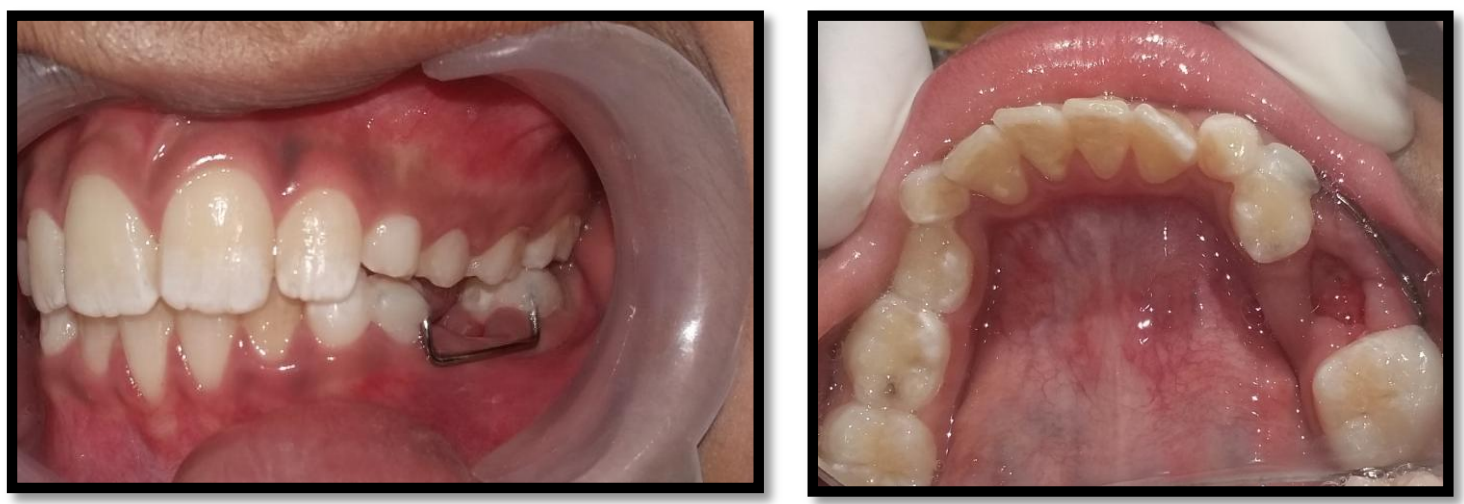

Fig-1: Bonded space maintainer

\section{Case-2}

The second case is of an 8 year old male patient reported to the department of Pedodontics and Preventive Dentistry with the complain of decayed tooth. For this case after extraction of the primary second molar under local anesthesia, complete aseptic and sterile conditions by applying the principles of extraction a Mayne's appliance was delivered banding the permanent first molar. Stainless steel 19 gauge wire was used to construct a modified loop. This loop spanned the edentulous area to contact mesial abutment just below the contact point and a solder ball was placed at the end to prevent injury from sharp edge of wire end, this prevents interference with permanent successor (Figure-2). The other end of the loop was soldered to the band which was luted to the permanent first molar. Patient was instructed to not to eat or drink for $30 \mathrm{~min}$ and not to bite on any hard food. The patient was recalled at regular intervals for check-up.

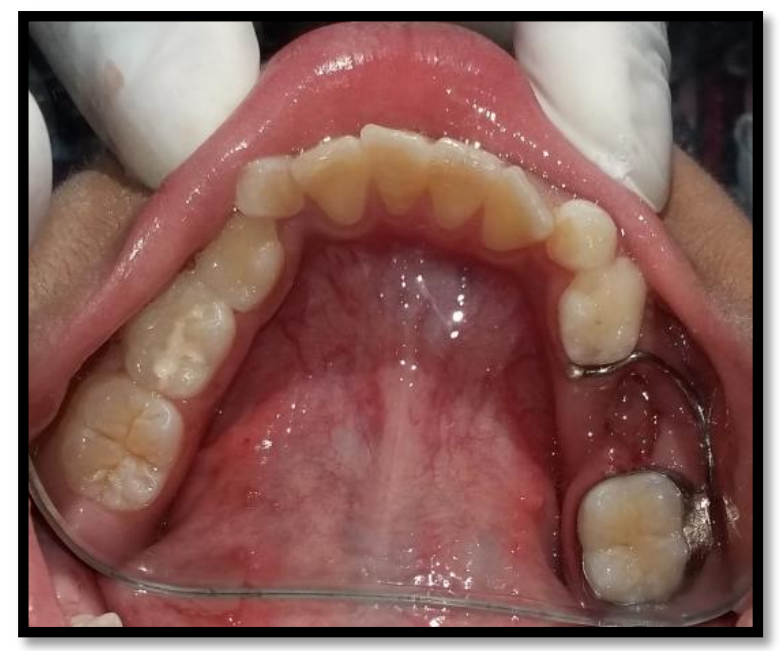

Fig-2: Mayne's appliance

Case-3

A 8 year old patient reported to the Department of Pedodontics and Preventive Dentistry with the complain of multiple carious. On examination root stumps were present in relation to right and left lower primary first molars, a treatment plan of extraction followed by placement of space maintainer was planned. After extraction the of the left primary first molar a regular band and loop space maintainer was placed banding the permanent molar. On the right side the pulpectomy followed by stainless steel crown was placed on second primary molar. Due to distal drifting of the canine a modified loop was planned, a u loop was constructed using 19 gauge stainless steel wire and the loop was used to regain the space lost. The distal end of the wire was bonded to the permanent first molar distally and the mesial end of the wire was made to encircle the canine from the center of the lingual surfacejust below the cingulum. The patient was recalled on regular intervals for follow up and adjustment of the $\mathrm{U}$ loop.

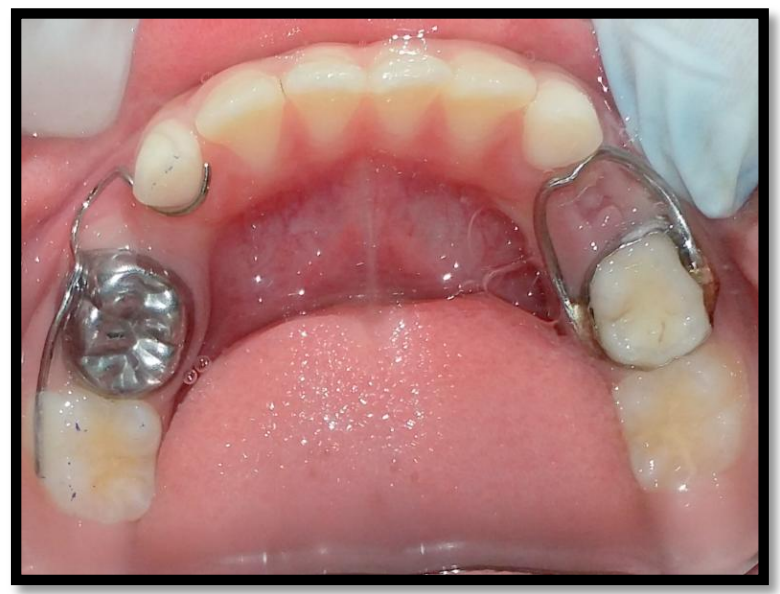

Fig-3: Bonded space maintainer with U loop for regaining space

\section{DISCUSSION}

To maintain the arch integrity and provide guidance to the succedenous teeth the presence of healthy primary dentition is of utmost importance. Studies state that the premature loss of the primary mandibular first molar results in drifting of the primary mandibular canine distally [3]. That can be appreciated in our third case figure 3 wherein the U-loop has been incorporated to open up the space lost due to the distal drifting of the canine. In this case series we have 
reported three patients having missing primary first and primary second molar. Premature loss of a primary first molar can result in loss of space of approximately 1.5 $\mathrm{mm}$ in the mandible and $1 \mathrm{~mm}$ in the maxilla [4]. The primary second molar plays an important role in preserving leeway space and an actively erupting first permanent molar will migrate mesially if there is a missing primary second molar [5]. Hence in the second case to limit the migration of the permanent molar a Mayne's appliance was placed. Mayne's appliance was first designed by Mayne. It is a type of non-functional space maintainer consisting of a bar or crib arrangement that follows the contour of the tissue and permits minor adjustments for space control while the tooth in question is erupting. The basic band and loop design can be modified in such a way as to not interfere with the eruption of a permanent successor [6].

The conventional band and loop space maintainer is good in terms of easy fabrication, relatively lesser appointments, and fairly good patient acceptance. However in certain situations depending on the age of the patient, anatomic variation of tongue, maintainence of space for lesser duration modified band and loops can be advocated. Irrespective of whichever design is advocated space maintainers can accumulate plaque and predispose the patient to dental caries, hence careful patient selection is required with regular follow up are necessary. It is therefore essential to minimize the risk of caries through dietary advice, reinforcement of oral hygiene and application of fluoride varnish at a regular basis.

\section{CONCLUSION}

The band and loop space maintainer can be modified in different ways depending on the anatomic structure, duration of maintaining the space, age of the patient, the clinical condition, oral hygiene, and the cooperative nature of the patient. In conditions where there is difficulty in fabrication of a complete loop the unilateral loop can provide necessary support to the lost space.

Conflicts: There are no conflicts of interest

\section{REFERENCES}

1. Hammad, N. (2011). Space maintainers utilization by 6-7 years old girls in Riyadh Saudi Arabia. $J$ Pak Dent Assoc, 20(1), 23-28.

2. Srivastava, N., Grover, J., \& Panthri, P. (2016). Space maintenance with an innovative "Tube and loop" space maintainer (Nikhil Appliance). International journal of clinical pediatric dentistry, 9(1), 86-89.

3. Kumari, P., \& Kumari, R. (2006). Loss of space and changes in the dental arch after premature loss of the lower primary molar: A longitudinal study. Journal of Indian Society of Pedodontics and Preventive Dentistry, 24(2), 90- 96.

4. Tunison, W., Flores-Mir, C., ElBadrawy, H., Nassar, U., \& El-Bialy, T. (2008). Dental arch space changes following premature loss of primary first molars: a systematic review. Pediatric dentistry, 30(4), 297-302.

5. Gianelly, A. A. (1995, September). Leeway space and the resolution of crowding in the mixed dentition. In Seminars in orthodontics (Vol. 1, No. 3, pp. 188-194). WB Saunders.

6. Grabber, T. M. (1972). Orthodontic Principle and Practice. 3rd ed. Philadelphia: Saunders; p. 650652. 